\title{
Constrictive pericarditis - A challenging diagnosis
}

\author{
Vittal Hejjaji*1, Claire Sullivan², Jun Li², Brian D. Hoit ${ }^{2}$ \\ ${ }^{1}$ Department of Internal Medicine, University Hospitals Cleveland Medical Center, Cleveland, United States \\ ${ }^{2}$ Divison of Cardiovascular Medicine, Harrington Heart and Vascular institute, Cleveland, United States
}

Received: June 1, 2017

DOI: $10.5430 /$ crim.v4n3p25

\author{
Accepted: June 11, 2017 \\ Online Published: June 21, 2017 \\ URL: https://doi.org/10.5430/crim.v4n3p25
}

\begin{abstract}
Constrictive pericarditis is a challenging diagnosis. This case report describes a patient with constrictive pericarditis (CP) secondary to radiation therapy. As the patient presented with non-specific symptoms, various modalities (both invasive and non-invasive) were used in the diagnosis and differentiation of CP from restrictive cardiomyopathy (RCM). This case of surgicallyproven $\mathrm{CP}$ demonstrates that a high clinical suspicion based on physical findings should be combined with multiple diagnostic modalities in the diagnosis of CP. It is crucial to differentiate CP from RCM due to the significant variance in treatment.
\end{abstract}

Key Words: Constrictive pericarditis, Echocardiography, Radiation, Restrictive cardiomyopathy, Diagnosis

\section{INTRODUCTION}

The pericardium is a fibrous sac surrounding the heart that consists of two layers: the visceral and parietal pericardium. With some variability, the thickness of the normal pericardium as measured on computed tomography (CT) and magnetic resonance imaging (MRI) is less than $2 \mathrm{~mm} .{ }^{[1]} \mathrm{Pa}-$ tients with constrictive pericarditis $(\mathrm{CP})$ present with clinical features of congestive heart failure with right-sided features being more prominent than left-sided heart failure symptoms. More commonly, patients present with non-specific symptoms and different types of diagnostic modalities are needed to confirm the diagnosis. It is important to differentiate $\mathrm{CP}$ from restrictive cardiomyopathy (RCM) as both can present with similar symptoms but have dramatically different treatment modalities. The diagnosis and differentiation of these diseases can be quite challenging and we describe a case in which we were compelled to use multiple diagnostic tests to clinch the diagnosis.

\section{Case presentation}

The patient is a 54-year-old man with a history of hypertension, coronary artery disease and inferior wall myocardial infarction revascularized with a drug-eluting stent in the right coronary artery nine months prior to presentation, and myasthenia gravis treated with thymectomy and radiation. The patient was hospitalized multiple times for shortness of breath and underwent numerous thoracenteses, but the etiology of recurrent pleural effusions had not been identified. Pertinent findings on physical exam included elevated jugular venous pulse, pericardial rub without evidence of murmur, ascites, and bilateral lower extremity edema. Chest $\mathrm{X}$-ray showed bilateral pleural effusions. Kussmaul's sign was negative.

Transthoracic echocardiography (TTE) demonstrated a septal bounce during inspiration, dilated and non-compressible inferior vena cava (IVC), and a thickened posterior pericardium (8-10 mm). Notably, TTE showed normal left ventricle (LV) inflow velocities and no annulus paradoxus. CT of the chest showed significant thickening and calcification of the pericardium and mediastinum secondary to radiation as well as a dilated superior vena cava and IVC (see Figure 1).

Cardiac MRI demonstrated calcification adjacent to the left

\footnotetext{
*Correspondence: Vittal Hejjaji; Email: vittal.hejjaji@uhhospitals.org; Address: Department of Internal Medicine, University Hospitals Cleveland Medical Center, 30 Severance Cir, Apt 108, Cleveland Heights, OH 44118, United States.
} 
atrioventricular groove and the anterior aspect of the LV and right ventricle (RV), septal bounce, and exaggerated inspiratory septal flattening suggestive of constrictive physiology. LV ejection fraction was preserved at $55 \%$ and there was no pericardial effusion. Heart catheterization was performed showing discordance with an inspiratory rise in RV pressure and concomitant drop in LV pressure (see Figure 2). Un-

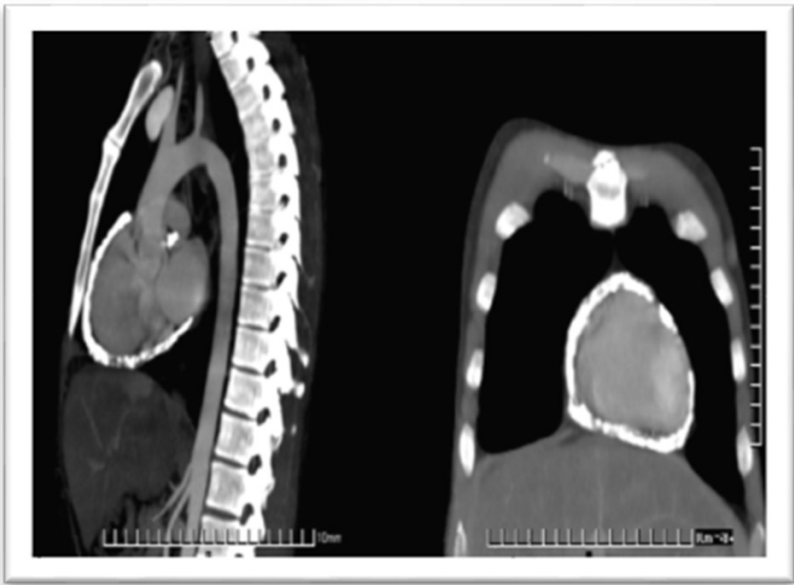

fortunately, most of the discordant waves were associated with premature ventricular contractions preventing definitive assessment of discordance in the catheterization lab. Upon arriving at the diagnosis of $\mathrm{CP}$, The patient was evaluated by thoracic surgery and underwent anterior pericardiectomy with improvement in symptoms and resolution of pleural effusions.

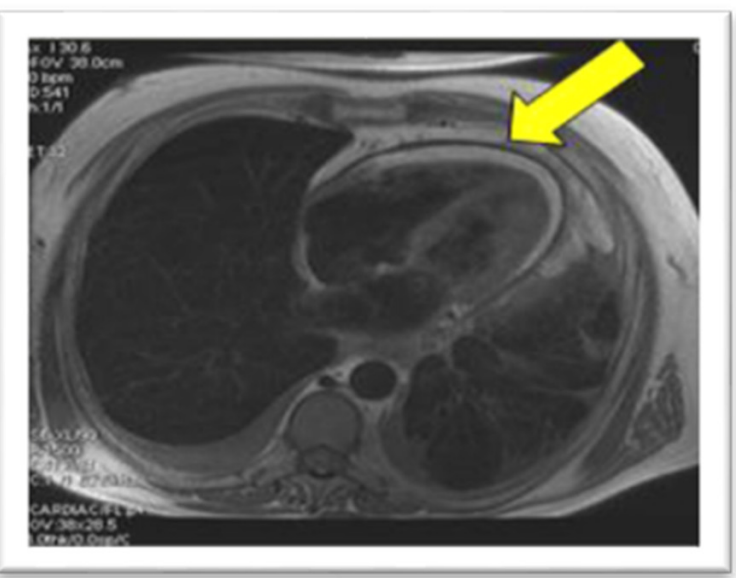

Figure 1. CT scan showing thickened and calcified pericardium

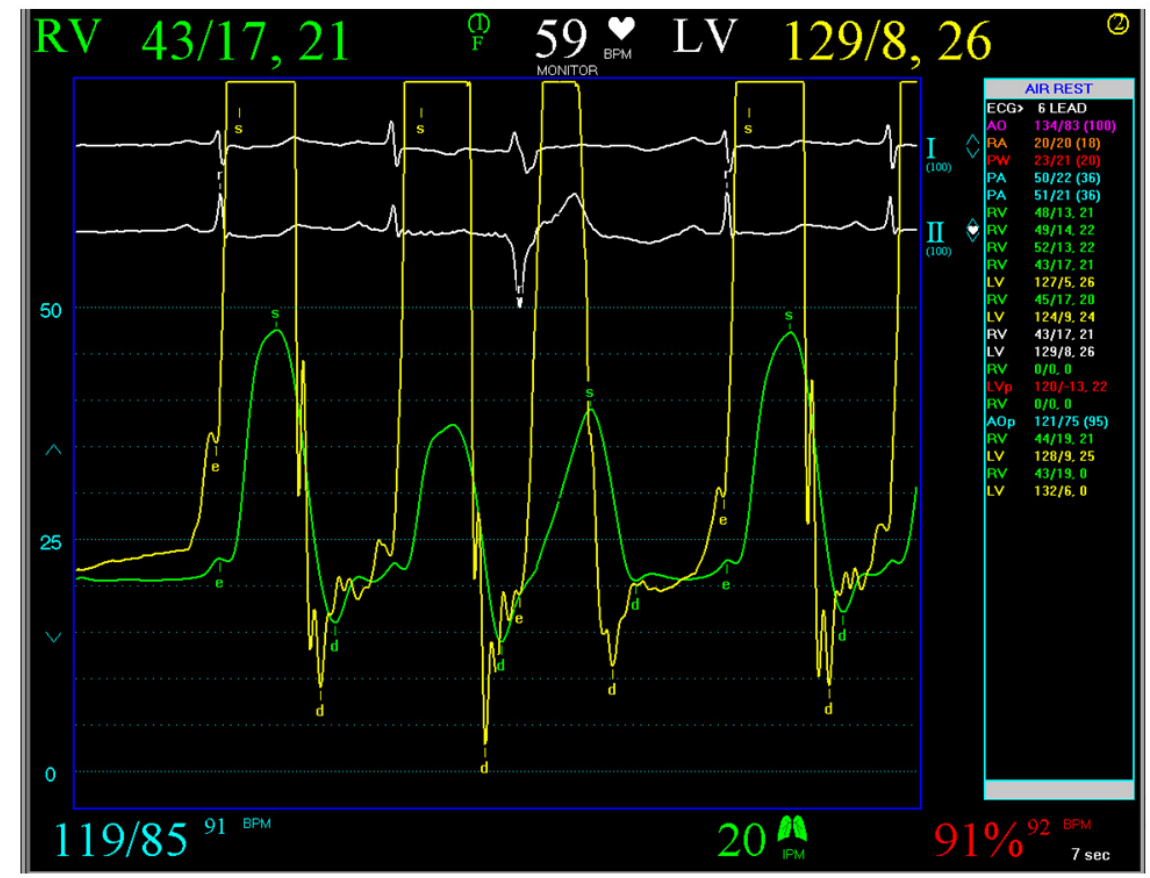

Figure 2. Right heart catheterization showing discordance in the pressure waves with premature ventricular contractions

\section{Discussion}

$\mathrm{CP}$ is the result of a number of disease processes causing pericardial inflammation. Radiation exposure accounts for nearly $31 \%$ of cases of CP. ${ }^{[2]}$ Pathologically, there is thicken- 
With CP, the stiffened pericardium prevents the ventricles from relaxing and forces ventricular filling to be dependent on each other (ventricular interdependence) leading to reduced filling. During inspiration, the interventricular septum shifts to the left because of decreased LV filling, during expiration, the increased filling of the LV forces the septum to return back to normal. This abnormal septal variation during respiration, which is most prominent in early diastole, is called a "septal bounce" and is a characteristic feature in CP that can be seen on TTE and cardiac MRI. ${ }^{[3-5]}$ Mitral valve (MV) and tricuspid valve (TV) peak flow velocities are also affected during respiration with $\mathrm{CP}$. This respiratory variation is not seen in RCM thus helping in differentiating the two disease processes.

CT scan is another imaging modality used to differentiate between CP and RCM. CT provides a reliable assessment of pericardial calcification and thickness. The primary disadvantage of a CT scan is that it cannot be used to evaluate the ventricular function and hemodynamic parameters. ${ }^{[6]}$ For this reason, physicians often obtain both a CT scan and a TTE when evaluating for CP. Cardiac MRI is another imaging modality often utilized and the finding of interventricular dependence can differentiate $\mathrm{CP}$ from $\mathrm{RCM}^{\left[{ }^{[7]}\right.}$

It is not uncommon for the pericardium of patients with $\mathrm{CP}$ to appear normal on imaging studies and physical examina- tion. ${ }^{[8]}$ This is when heart catheterization may be necessary to make the diagnosis. ${ }^{[9]}$ In this case, the TTE, CT scan, and heart catheterization showed a few features of $\mathrm{CP}$ but failed to provide a definitive diagnosis. Cardiac MRI sealed the diagnosis which was later proven during surgery.

Pericardiectomy is the only definitive treatment option for patients with chronic symptomatic $\mathrm{CP}$; patients with only mild symptoms and those with end-stage disease are not suitable candidates. ${ }^{[10]}$ Although curative, there is documented evidence of significant mortality with this procedure and so the diagnosis needs to be confirmed before proceeding with treatment. ${ }^{[11,12]}$ Long-term survival post-pericardiectomy in patients who developed the disease due to prior ionizing radiation has shown to be lower compared to other etiologies of $\mathrm{CP} \cdot{ }^{[13]}$ This is probably due to permanent myocardial damage induced by the radiation in addition to the pericardial damage resulting in a mixed, restrictive, and constrictive disease pattern.

Radiation can cause both CP and RCM. The patient's case is unique as it highlights the multiple different modalities that were utilized to confirm the diagnosis and thus guiding us in providing the appropriate form of treatment.

\section{CONFliCtS OF INTEREST Disclosure}

The authors have declared no conflicts of interest.

\section{REFERENCES}

[1] Bull RK, Edwards PD, Dixon AK. CT dimensions of the normal pericardium. Br J Radiol. 1998; 71: 923-5. PMid:10195005 https://doi.org/10.1259/bjr.71.849.10195005

[2] Cameron J, Oesterle SN, Baldwin JC, et al. The etiologic spectrum of constrictive pericarditis. Am Heart J. 1987; 113: 354. https://doi.org/10.1016/0002-8703(87) 90278-X

[3] Rajagopalan N, Garcia MJ, Rodriguez L, et al. Comparison of new Doppler echocardiographic methods to differentiate constrictive pericardial heart disease and restrictive cardiomyopathy. Am J Cardiol. 2001 Jan 1; 87(1): 86-94. https://doi .org/10.1016/S0002-9 $149(00) 01278-9$

[4] Hatle LK, Appleton CP, Popp RL. Differentiation of constrictive pericarditis and restrictive cardiomyopathy by Doppler echocardiography. Circulation. 1989 Feb; 79(2): 357-70. PMid:2914352 https://doi.org/10.1161/01.CIR.79.2.357

[5] Francone M, Dymarkowski S, Kalantzi M, et al. Assessment of ventricular coupling with real-time cine MRI and its value to differentiate constrictive pericarditis from restrictive cardiomyopathy. Eur Radiol. 2006; 16: 944-51. PMid:16228208 https://doi.org/10.1007/ s00330-005-0009-0

[6] O'Leary SM, Williams PL, Williams MP, et al. Imaging the pericardium: appearances on ECG-gated 64-detector row cardiac computed tomography. Br J Radiol. 2010; 83: 194-205. PMid:20197434 https://doi.org/10.1259/bjr/55699491

[7] Giori B, Mollett NRA, Dymarkowski S, et al. Assessment of ventricular septal motion in patients clinically suspected of constrictive pericarditis, using magnetic resonance imaging. Radiology. 2003; 228: 417-24. PMid:12802001 https://doi.org/10.1148/radi ol. 2282020345

[8] Talreja DR, Edwards WD, Danielson GK, et al. Constrictive pericarditis in 26 patients with histologically normal pericardial thickness Circulation. 2003; 108: 1852. PMid:14517161 https://doi.org/ 10.1161/01.CIR.0000087606.18453.FD

[9] Talreja DR, Nishimura RA, Oh JK, et al. Constrictive pericarditis in the modern era: novel criteria for diagnosis in the cardiac catheterization laboratory. J Am Coll Cardiol. 2008 Jan 22; 51(3): 315-9. PMid:18206742 https://doi.org/10.1016/j.jacc.2007.09 .039

[10] Tettey M, Sereboe L, Aniteye E, et al. Surgical management of constrictive pericarditis. Ghana Med J. 2007 Dec; 41(4): 190-3. PMid: 18464907

[11] Kushibe K, Kitamura S, Kawachi K, et al. Surgical treatment for chronic constrictive pericarditis through a combined median sternotomy and left anterolateral thoracotomy. Rinsho Kyobu Geka. 1989 Oct; 9(5): 494-7. PMid:9301963

[12] Oku T, Sawada Y, Minohara S, et al. Easy dissection of hard and thickened pericardium on constrictive pericarditis. Ann Thorac Surg. 1990 Dec; 50(6): 998-9. https : //doi .org/10 .1016/0003-497 5 (90) $91146-3$

[13] Thambidorai SK, Parakh K, Schoenhagen P, et al. Constrictive pericarditis: Etiology and cause-specific survival after pericardiectomy. J Am Coll Cardiol. 2004; 43(8): 1445. PMid:15093882 https://doi.org/10.1016/j.jacc.2003.11.048 